\title{
Ageing perception in seniors' formal caregivers
}

\begin{abstract}
This paper explores the ageing perception of a group of seniors' caregiver workers, particularly those who have direct contact with the elderly while performing their tasks. Therefore, we analyze the variables that influence this perception and the ones that can be good predictors. One hundred and forty-eight individuals took part in this study (a hundred and thirty- five females and twelve males) with ages between twentyone and sixty-five years old. It was applied the Portuguese versions of the tests Ageing Perception Questionnaire, the Self-Concept Scale (TSCS:2) and a sociodemographic questionnaire. The results showed that the ageing perception is more negative as age advances. On the other hand, individuals with higher education, training in the health field or with a stronger self-concept have a more positive ageing perception. The studied variables that best predict the emotional representation for ageing are the academic qualifications and the academic self-concept.
\end{abstract}

Volume 3 Issue 2 - 2018

\author{
Beja MJ,' Franco G,' Sousa JM,' Candeias \\ $A A,{ }^{2}$ Aveiro $S^{\prime}$ \\ 'Department of Psychology, University of Madeira, Portugal \\ ${ }^{2}$ Department of Psychology, University of Évora, Portugal \\ Correspondence: Maria João Beja, Department of Psychology, \\ University of Madeira, Campus da Penteada, 9020-105, Funchal, \\ Portugal, Email maria.joao.beja@staff.uma.pt
}

Received: December 01, 2017| Published: March 13, 2018

Keywords: ageing, elderly, self-concept, aging perception, formal caregiver

Abbreviations: ACA, academic/work self-concept; AP, ageing perception; APQ, ageing perception questionnaire; $\mathrm{BHV}$, behavior self-concept; CI, confidence interval; CSN, consequences-negative; CSP, consequences-positive; CTN, control-negative; CTP, controlpositive; ER, emotional-representations; ES, effect size; FAM, family self-concept; ID, identity (APQ); IDN, identity (TSCS:2); MOR, moral self-concept; PER, personal self-concept; SAT, satisfaction; SOC, social self-concept ; TCH, timeline-chronic; TCY, timelinecyclical.

\section{Introduction}

Ageing perception is a product of life experiences, education, beliefs, ideas, preconceptions and stereotypes, ${ }^{1}$ that are equally at the base of the construction of each person's self-concept, shaped throughout life. Research has shown older adults' self-perceptions of ageing as predictors of physical health, quality of life (QoL) and even mortality. And these influences can happen via behavioral, psychological and physiological pathways. ${ }^{2}$

Of the various life cycle stages an individual may live through, old age may be perceived as the one with most negative aspects. Based on this, it is particularly relevant to develop interventions that focus on changing the perception of aging, making it a more positive one. This will impact individuals' psychological wellbeing and influence their health.

Working directly with elderly requires specific knowledge and skills, as well as a predisposition to humanize tasks to be performed, although it is known that professionals may have negative attitudes towards elderly. ${ }^{3}$ The manner in which each individual perceives his own ageing will influence, not only his own ageing process and but also the care given to and attitudes towards elderly. ${ }^{3}$

\section{Materials and methods}

In our study participated 148 subjects from a nursing home (age range $21-65$ years; $\mathrm{M}=45.78 ; \mathrm{SD}=0.90)$. They were mainly women $(91,2 \%)$ working at direct support and care $(63,5 \%)$, kitchen facilities
$(11,5 \%)$, nursing care $(8,8 \%)$, physiotherapy $(5,4 \%)$, other functions $(10,1 \%)$. Almost one third of the sample $(31 \%)$ had secondary or higher education, with $26,4 \%$ having third level education, $12,2 \%$ having second level education, and $25,7 \%$ having primary education or even less. This study used tree measures: Sociodemographic Questionnaire, Aging Perceptions Questionnaire (APQ), Tennesse Self-Concept Scale (TSCS:2).

Aging Perceptions Questionnaire (APQ), a multi-dimensional measure based in Leventhal's self-regulation model, ${ }^{4}$ is a selfcompletion questionnaire, adapted to Portuguese. ${ }^{5}$ The APQ measure comprises 32 Likert scale items that represent eight ageing perception domains: identity (ID), timeline-chronic TCH), timeline-cyclical (TCY), consequences-positive (CSP), consequences-negative (CSN), control-positive (CTP), control-negative (CTN) and emotionalrepresentations (ER). The reliability of this measure in this study, Cronbach's alpha, is situated between .60 e .88 , indicating fair reliability in two domains and good reliability in the others six domains.

The Tennesse Self-Concept Scale: Second Edition (TSCS:2), developed by Roid and Fitts in 1989 and adapted to portuguese by Novo, ${ }^{6}$ comprises 82 items grouped in 10 subscales. Internal dimension: identity (IDN), satisfaction (SAT), behavior (BHV); external dimension: physical self-concept (PHY), moral self-concept (MOR), personal self-concept (PER), family self-concept (FAM), social self-concept (SOC) and academic/work self-concept (ACA). In this study TSCS:2 presents reliability scores, Cronbach's alpha, varying between .68 e .92 , which indicate fair and good reliability.

During data collection, the ethical parameters of the Portuguese Psychologists Board ${ }^{7}$ were followed. Authorization was requested from the authorities responsible for the institution, each individual manifested his informed consent, and all retrieved data was anonymous and confidential. Statistical data processing was done with resort to the SPSS programme, having been performed parametric and nonparametric tests to ensure the normality of the variables. The analysis took place with a confidence interval (CI) of $95 \%$, having also been determined the effect size (ES) in some cases. 


\section{Results and discussion}

The rresults of a Mann-Whitney analysis revealed that middle aged adult group ( 41 to 65 years) has a more negative outlook on ageing than the group of young adults (21 to 40 years) according to the scales of ID $\left(U=764, p<.001, r_{G=} .61\right), \operatorname{CTN}\left(U=1521, p<.001, r_{G}\right.$ $=-.36)$, TCY $\left(U=1568.5, p<.001, r_{G}=.34\right), \operatorname{CSN}(U=1611, p=.001$, $\left.r_{G=} .32\right), \operatorname{ER}\left(U=1646, p=.001, r_{G=} .30\right), \mathrm{TCH}\left(U=1940, p=.050, r_{G}\right.$ $=.18$ ). These results may simply not only a less adaptive perception of ageing as well as a lower sensation of wellbeing in regard to this process. ${ }^{8,9}$

The influence of academic qualifications on AP, measured by Kruskall-Wallis test, is visible in TCY $\left(X^{2}(3)=14.70, p=.002\right)$, ER $\left(X^{2}(3)=16.50, p=.001\right)$, in $\mathrm{CTN}\left(X^{2}(3)=15.43, p=.001\right), \mathrm{CSN}$ $\left(X^{2}(3)=13.75, p=.003\right)$ and identity $\left(X^{2}(3)=24.33, p<.001\right)$. Subjects that detain the $1^{\text {st }}$ cycle of schooling of the Portuguese educational system, have a more negative outlook, whilst those that hold higher education present a more positive vision. This may be explained by the fact that a lower academic level may be a facilitator of the internalization of stereotypes in regard to ageing. ${ }^{10}$ The relationship between knowledge on ageing and attitudes towards it will depend on how positive this knowledge is, meaning that higher levels of positive knowledge are linked to a decrease of anxiety in regard to ageing. ${ }^{11}$

Significant differences were also found, using $=U$ de Mann-
Whitney test, between professionals with and without training in the medical field in CTN $\left(U=674.5, p<.001, r_{G}=.56\right), \operatorname{CSN}(U=1002$, $\left.p=.005, r_{G=}=.34\right), \mathrm{ID}\left(U=837, p=.010, r_{G}=-.34\right)$, ER $(U=1039$, $\left.p=.008, r_{G=}=.32\right)$ and CTP $\left(U=1179.5, p=.042, r_{G=} .23\right)$. Those who hold training in the medical field present a significantly greater control in regard to negative aspects that come with ageing, perceive less negative consequences and withhold fewer negative emotions in regard to ageing, which indicates a more positive self-perception of ageing.

This relation may be the outcome of a more realistic, less stereotyped perception of the ageing process and of the elderly. ${ }^{12,13} \mathrm{On}$ the other hand, seniors' caregiver workers generally have a distorted perception in regard to the ageing process and tend to see old age more negatively than the elderly themselves. ${ }^{14,15}$

It is possible to conclude in this study, from the relationship between self-concept and ageing perception, that individuals with greater selfconcept have a lower negative emotional response to ageing, greater belief of control over negative experiences that come with age, fewer health changes and are less likely to attribute those alterations to their ageing process. The results obtained in the link between self-concept and ageing perception, and the fact that both are influenced by age, in this study, may be explained by stereotypes on ageing, that are built and internalized throughout life, and contribute to a more negative ageing perception of oneself and lower self-concept. ${ }^{16}$

Table I Summary of multiple regression models for sociodemographic variables and self-concept dimensions as predictors of emotional representation

\begin{tabular}{|c|c|c|c|c|c|c|}
\hline \multirow{2}{*}{ Parameters } & \multicolumn{2}{|c|}{ Standardized coefficients $(\boldsymbol{\beta})$} & \multirow{2}{*}{$\mathbf{R}$} & \multirow{2}{*}{$\mathbf{R 2}$} & \multirow{2}{*}{ R2(Adjusted) } & \multirow{2}{*}{$\mathbf{F}$} \\
\hline & Model I & Model II & & & & \\
\hline I - Saciodemographic & & & 0.33 & 0.109 & 0.089 & $5.42 * *$ \\
\hline \multicolumn{7}{|l|}{ variables } \\
\hline Age & 0.059 & 0.028 & & & & \\
\hline Qualifications & -.279 & -0.096 & & & & \\
\hline Work Area & -0.018 & -0.057 & 0.5 & 0.254 & 0.201 & $4.79 * * *$ \\
\hline \multicolumn{7}{|l|}{ II - Self-Concept } \\
\hline Physical Self-Concept & & -0.116 & & & & \\
\hline Moral Self-Concept & & -0.17 & & & & \\
\hline Personal Self-Concept & & 0.154 & & & & \\
\hline Family Self-Concept & & -.080 & & & & \\
\hline Social Self-Concept & & -044 & & & & \\
\hline Academic/Work Self-Concept. & & $-.228^{*}$ & & & & \\
\hline
\end{tabular}

Note. $\mathrm{n}=137$

$* \mathrm{p}<.05 ; * * \mathrm{p}<.01 ; * * * \mathrm{p}<.001$

Because ER accesses the emotional response induced by ageing through negative feelings such as anger, fear, depression, anxiety, worry and sadness, and it has been linked to negative health changes a low resilience, ${ }^{4}$ we set out to determine what the influence of sociodemographic variables and the dimensions of self-concept were in its explanation. The results of a Multiple Regression (Table 1) show that the parameters that are greater predictors are academic levels $(\beta$ $=-.2 .79)$ and ACA $(\beta=-.228)$. The combination of these variables predicts that $20.1 \%\left(R^{2}\right)$ with a decrease of $5.3 \%$ in relation to an adjusted R2 $\left(R^{2}=25.4 \%\right)$. Model I (sociodemographic variables) explains $8.9 \%$ of the variance $(F(3.133)=5.42, p=.002)$ and model II (dimensions of self-concept) explains $11.2 \%$ of the variance in emotional representation $(F(9.127)=4.79, p<.001)$, which according to $\mathrm{Cohen}^{17}$ is a moderate effect (Table 1). In this manner, a greater level of education and a higher perception of competence in work and study, means a lower underlying emotional representation from ageing processes, which is congruent with other studies. ${ }^{10,13,18}$

\section{Conclusion}

Older adults present a more negative ageing perception, on the other hand, individuals with higher academic levels and training in the medical field have a more positive perception of ageing. In the same manner, subjects that have a stronger academic self-concept present a more positive outlook on ageing. It is important to highlight that the best predictors of negative emotional responses to ageing, after multivariate analysis, were academic levels and academic selfconcept, which have implications in the importance that education and training have in the change of perception and attitudes towards old age. In this manner, increasing knowledge makes people and 
institutions have a more positive and realistic outlook on the elderly and old age. Education is the most important promoting agent for new behaviours and forms of thinking, changing social and individual expectations towards old age.

It is suggested that the more qualified professionals of the institutions, such as doctors, psychologists, nurses, physiotherapists and social workers, promote training programmes towards the other professionals in order to contribute towards the demystification of some preconceptions regarding ageing, and to a greater knowledge towards the elderly in their physical, psychological and social dimension, as unique beings. This will help the relationship between elderly and professional to become a co-construction that leads to greater satisfaction and quality of life.

In the given context, it proves to be of importance the conduction of research on ageing perception in different age categories, not only in advanced adult age, for ageing is an individual process that accompanies us from birth. Stereotypes and preconceptions towards elderly and old age should be combated from earlier age brackets, ensuring that throughout the development and ageing process, each individual's self-concept is stronger and more conscious.

\section{Acknowledgements}

None.

\section{Conflict of interest}

Authors declare that there are no conflicts of interest.

\section{References}

1. Levy BR, Slade MD, Kunkel SR, et al. Longevity increased by positive self-perceptions of aging. J Pers Soc Psychol. 2002;83(2):261-270.

2. Sexton E, King KBL, Morgan K, et al. Development of the Brief Ageing Perceptions Questionnaire (B-APQ): a confirmatory factor analysis approach to item reduction . BMC Geriatrics. 2014;14:44.

3. Ballesteros F. La gerontologia positiva. Revista multidisciplinar de gerontologia. 200;10(3):143-145.

4. Barker M, O'Hanlon A, McGee H, et al. Cross-sectional validation of the Aging Perceptions Questionnaire: a multidimensional instrument for assessing self-perceptions of aging. BMC Geriatric. 2007;7:9.
5. Beja MJ, Franco. Questionário sobre percepções de envelhecimento (QPE) (Instrumento de avaliação psicológica não publicado); 2009.

6. Novo R. Para além da Eudaimonia - O Bem-estar Psicológico em mulheres na idade Adulta avançada. Lisboa: Fundação Calouste Gulbenkian; 2003.

7. Ordem dos Psicólogos Portugueses. Código Deontológico. Lisboa: Ordem dos Psicólogos Portugueses; 2011.

8. Steverink N, Westerhof GJ, Bode C, et al. The personal experience of aging, individual resources, and subjective well-being. J Gerontol B Psychol Sci Soc Sci. 2001;56B(6):364-373.

9. Ron P .Elderly people's attitudes and perceptions of aging and old age: the role of cognitive dissonance? Int $J$ Geriatr Psychiatry. 2007;22(7):656-662.

10. Jan GY, Poon LW, Kim SY, et al. Self-perception of aging and health among older adults in Korea. Journal of Aging Studies. 2014;18:485696.

11. Foos P, Clark M, Terrell D. Adult Age, Gender and Race Group Differences in Images of Aging. J Genet Psychol. 2006;167(3):309-325.

12. Cachioni M, Aguilar L. Crenças em relação à velhice entre alunos da graduação, funcionários e coordenadores - professores envolvidos com as demandas da velhice em universidades brasileiras. Kairós. 2008;11(2):95-119.

13. Fitzgerald JT, Wray LA, Halter JB, et al. Relating medical students' knowledge, attitudes, and experience to an interest in geriatric medicine (Abstract). The Gerontologist. 2003;43(6):849-855.

14. Trentini CM, Chachamovich E, Figueiredo M, et al. A percepção de qualidade de vida do idoso avaliada por si próprio e pelo cuidador. Estudos de psicologia. 2006;11(2):191-197.

15. Sampaio A, Rodrigues F, Pereira V, et al. Cuidadores de Idosos: percepção sobre o envelhecimento e sua influência sobre $o$ ato de cuidar. Estudos e pesquiças em psicologia. 2011;11(2):590-613.

16. Rocha L. Tradução e Adaptação Cultural do Aging Perceptions Questionnaire (APQ) para a Língua Portuguesa Brasileira (Dissertação de Mestrado); 2010.

17. Field A. Discovering Statistics Using SPSS. 3rd ed. London: SAGE; 2011.

18. Coleman, O Hanlon. Aging and Development. 2nd ed. London: Routleged; 2017. 